\title{
Job Satisfaction among Indian Pharmacists: An Exploration of Affecting Variables and Suggestions for Improvement in Pharmacist Role
}

\author{
Akram Ahmad"1, Muhammad Umair Khan', Ramadan Mohamed Elkalmi², Shazia Qasim Jamshed², \\ Anantha Naik Nagappa ${ }^{3}$, Isha Patel ${ }^{4}$ and Rajesh Balkrishnan ${ }^{5}$
}

${ }^{1}$ Department of Clinical Pharmacy, UCSI University, No. 1 Jalan Menara Gading, Taman Connaught, Cheras 56000, Kuala Lumpur, Malaysia.

${ }^{2}$ Department of Pharmacy Practice, Kulliyyah of Pharmacy, International Islamic University Malaysia, Kuantan Campus, Pahang 25200, Malaysia.

${ }^{3}$ Department of Pharmacy Management, Manipal College of Pharmaceutical Sciences, Manipal University, Manipal 576104, India. ${ }^{4}$ Department of Biopharmaceutical Sciences, Shenandoah University, Bernard J Dunn School of Pharmacy, 1775 N Sector Ct, Winchester, VA 22601, USA.

${ }^{5}$ Department of Public Health Sciences, University of Virginia School of Medicine, Charlottesville, VA, USA.

\begin{abstract}
Objectives: The purpose of this study was to determine the level of job satisfaction among Indian pharmacists, and factors associated with job satisfaction. The study also explored the suggestions of pharmacist to improve the profession of pharmacy in India. Methods: A cross sectional web-based study was conducted on working pharmacists in India, using a validated questionnaire for a period of 2 months. The participants were contacted via email and social websites and data was collected by using web-based survey. The data were coded and entered to statistical package for social sciences (SPSS) version 20. The responses to the questionnaire were analyzed by performing descriptive and inferential statistics. Results: The satisfaction rate of pharmacists was $17.5 \%$. Similar numbers of pharmacist were satisfied with promotional opportunities at their workplace. $68.7 \%$ participants believed the reason for dissatisfaction was irresponsible government policies which hamper pharmacists from seeking jobs compared with other professionals. Majority of pharmacists agreed with the suggestion of determining payscale on the basis of both qualification and experience $(85.1 \%)$ followed by $84.8 \%$ who agreed that pharmacy degree should be deemed essential to acquire registration. Age, qualification and practice setting were significantly associated with differences in mean satisfaction score $(p<0.05)$. Conclusion: In this study, pharmacists were not satisfied with their jobs. A nation-wide study is warranted to further establish the satisfaction of pharmacists with their jobs. A further need to look at the intrinsic and extrinsic factors associated with pharmacist satisfaction can aid the development of suitable interventions to improve the same.
\end{abstract}

Key words: factors, India, job satisfaction, pharmacists, Survey, questionnaire.

\section{INTRODUCTION}

Job satisfaction is the degree of favorableness with which employees view their work. It is an important contributing factor towards a person's motivation and productivity. ${ }^{1-3}$ Job satisfaction is a factor that influences whether an employee will remain in a position or seek work elsewhere. ${ }^{4}$ Furthermore, job satisfaction can influence the quality of work produced. ${ }^{5}$ A lower level of job satisfaction is directly associated with lower life satisfaction. ${ }^{6}$

Job satisfaction affects the lives of all workers, including health workers. Both job satisfaction and motivation play an important role in job retention and increased produc-
Submission Date : 18-06-2015 Revision Date : :01-09-2015 Accepted Date : :24-08-2015

DOI: 10.5530/ijper.50.1.2 Correspondence: Dr. Akram Ahmad Department of Clinical Pharmacy, UCSI University, Kuala Lumpur, Malaysia.

Email:akrampharma67@ gmail.com

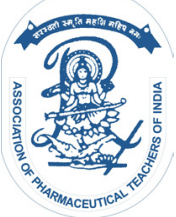

www.ijper.org 
tivity of health workers which in turn improves health system performance. ${ }^{7-8}$ Difficulty in retaining clinical staff in low and middle-income countries makes the already inadequate health care system more fragile. Thus, pharmacists' satisfaction with their work affects not only employees and employers, but also patients who receive the pharmacists' services. If the workers perceive that his/her values are realized within the job, his/her attitude and satisfaction towards his/her job will be more positive. ${ }^{9}$ However, with reference to the dissatisfaction, Schafheutle et al mentioned few domains which may influence job satisfaction such as working environment, working pattern working sector and other external pressures. In cases of dissatisfaction in such domains, pharmacist performance and quality of work is highly affected. The other important domain refers to physical and mental health including stress, depression, alcohol, cognitive impairment and other addictions. ${ }^{10}$ The findings of Schafheutle et al are also supported by another study which highlighted the association of job dissatisfaction with poor mental health. ${ }^{11}$ Job satisfaction can be measure in many ways, with variety of questions and wordings. However, there is no standard way to measure job satisfaction. A common item question regarding general job satisfaction is the most common one, however other multi-faceted questions are also considered as a common component of job satisfaction measurement. Researchers have also emphasized that measurement of job satisfaction can be a complex assessment as it may not be a simple average of workers' satisfaction in different aspect of a job. ${ }^{12}$ Similarly, Rose (2005) has also raised the issue of inadequacy of single-item overall job satisfaction measures compared with a composite measure of overall job satisfaction using several job facets. ${ }^{13}$ Pharmacists are the third largest healthcare professionals in the world and the pharmacy profession has been evolving steadily over the last decade in India. ${ }^{14}$ Pharmacists play a major role in providing the healthcare services in urban and rural areas, especially through community pharmacy where physicians are not available or are too costly for meeting the healthcare necessities, products and services. ${ }^{14,15}$ Today, the pharmacists had expanded their role from solely dispensing to pharmaceutical care by maximizing the benefits of the medication and its safety. With the increase in work related activities, it has directly or indirectly influenced the quality of work delivery and job satisfaction.

The pharmacy education and profession in India is regulated by the Pharmacy Council of India. Currently, near 1500 pharmacy schools offer a variety of pharmacy degrees like diploma in pharmacy ( 2 year community and hospital based program), bachelor of pharmacy (4 year industry oriented program) and doctor of pharmacy (6 years clinical oriented program). ${ }^{16}$ More than million people in India are pharmacists working in community pharmacy (55\%), in hospitals (20\%), in pharmaceutical and other industries $(10 \%)$, and in regulatory agencies $(1 \%)$, and academia $(2 \%)$. Within the last decade, pharmacy profession in India has evolved due to industrialization and patient needs have increased, thereby leading to an increase in the demand of the pharmacists. According to the Pharmacy Council of India (PCI), the ratio of pharmacist to patient was 1: 1856, which reveals a chronic shortage of pharmacists in India. ${ }^{15}$ A number of occupational surveys have been done in other countries about pharmacist's job satisfaction in academia, hospitals and community pharmacies. ${ }^{2-4,6-7}$ However, in India, very few studies have been conducted on the professional expectations and satisfaction of pharmacists. A pilot study conducted in India showed low satisfaction of pharmacist with their jobs. Lack of acknowledgement, salary, working environment and decrease opportunities to translate their skills into practice were the major factors contributed towards low satisfaction. ${ }^{17-18}$ The objective of this study was to determine the level of satisfaction among Indian pharmacists, and to explore the factors that influence job satisfaction of pharmacists in India.

\section{METHODOLOGY}

A cross sectional web based study was conducted for the period of 2 months to assess the job satisfaction among Indian pharmacists. Pharmacists from different sectors like hospitals, community, academia and industry were considered eligible to participate in this study. Sample size was calculated as 377 by using Raosoft calculator by keeping the power as $80 \%$, margin of error as $5 \%$, confidence interval as $95 \%$ and response distribution as $50 \%{ }^{19}$ A convenience sampling approach was adopted in which the respondents were recruited on easy accessibility. Participants were continued to be contacted until the required sample was achieved.

The Data were collected through web-based survey creation tool "Google document". The participants were contacted on their email addresses. Emails of the participants were obtained from Association of Community Pharmacist of India after approval of the study. Besides, researchers also use their personal contacts to approach to the professional pharmacists of India. Furthermore, the pharmacists were also contacted via various pharmacists groups like All India Pharmacist Association, Indian Academy of Pharmacists and Pharma times etc active on social networking sites like facebook.

The study instrument was designed by authors after a rigorous literature review,,$^{5-9,17-18}$ after which initial draft of the 
questionnaire was designed. This draft was then validated in two phases. In first phase, the questionnaire was sent to 3 pharmacy researchers for their opinion on the simplicity, relativity and importance of the questionnaire. In second phase, a pilot study was conducted by using a small sample of pharmacist $(n=30)$ who gave their opinions on making the questionnaire more brief and simple. After consideration of all the valid points extracted from both phases, final version of the questionnaire was approved by the authors and sent to participants for data collection. Reliability coefficient was calculated by using SPSS v.20 and the value of Cronbach's alpha was found to be 0.81 . The data of pilot study was not used for the final analysis. The questionnaire was divided into 4 parts. The first part asked the demographic information of the participants such as age, gender, highest qualification, type of pharmacist (community pharmacist, hospital pharmacist, academician pharmacist, student pharmacist and others) and salary paid. The second part evaluated the satisfaction of pharmacist. The third section explored the suggestions of pharmacist to improve future prac-

\begin{tabular}{|c|c|}
\hline Variable & $\begin{array}{c}\text { Response n } \\
(\%)\end{array}$ \\
\hline \multicolumn{2}{|l|}{ Age } \\
\hline $18-30$ & $340(90.18)$ \\
\hline $31-60$ & $37(9.82)$ \\
\hline \multicolumn{2}{|l|}{ Gender } \\
\hline Male & $300(79.57)$ \\
\hline Female & $77(20.42)$ \\
\hline \multicolumn{2}{|c|}{ Qualification } \\
\hline D. Pharm & $14(3.71)$ \\
\hline B. Pharm & $150(39.78)$ \\
\hline M. Pharm & $153(40.58)$ \\
\hline Pharm D & $44(11.67)$ \\
\hline $\mathrm{PhD}$ & $16(4.2)$ \\
\hline \multicolumn{2}{|c|}{ Practice Setting } \\
\hline Community & $130(34.5)$ \\
\hline Hospital & $151(40)$ \\
\hline Academia & $60(15.9)$ \\
\hline Industry & $32(8.6)$ \\
\hline Other & $4(1)$ \\
\hline \multicolumn{2}{|c|}{$\begin{array}{c}\text { Average Salary of respondents based on } \\
\text { Qualification (INR) }\end{array}$} \\
\hline D.Pharm & 6000 \\
\hline B.Pharm & 4500 \\
\hline M.Pharm & 8000 \\
\hline Pharm D & 12000 \\
\hline $\mathrm{PhD}$ & $25000-35000$ \\
\hline
\end{tabular}

tice, while the last part assessed the reasons of dissatisfaction among pharmacists. The number of questions included in each section was $6,10,8$ and 4 respectively. Data was entered in Microsoft Excel 2010 and was then coded and entered into SPSS (v.20) for statistical analysis. Descriptive analysis was carried out and data was expressed in frequency and percentage. Satisfaction questions were measured on a 4 point like rt scale of satisfaction. Points awarded to the responses were, $1=$ highly satisfied, $2=$ satisfied, $3=$ dissatisfied, $4=$ highly dissatisfied. Mean score of satisfaction was computed and the score of $\leq 2$ was considered as satisfactory. Inferential statistics (Mann-Whitney U test and Kruskal Wallis tests, $\mathrm{p}<0.05$ ) were also used to assess the significance among study variables. The study approved by Association of Community Pharmacist of India.

\section{RESULTS}

A total of 377 participants responded to the questionnaire, giving a response rate of $32.78 \%$. In this study 300 $(79.57 \%)$ respondents were males and $77(20.42 \%)$ were females. Majority of participants were younger than 30 years $(90.18 \%, \mathrm{n}=340)$. A large number of respondents had a qualification of Masters of Pharmacy (40.58\%, $\mathrm{n}=153)$ followed by Bachelors of Pharmacy $(39.78 \%$, $\mathrm{n}=150)$. Hospital pharmacists made a large portion of the sample $(40 \%, \mathrm{n}=151)$. The complete breakdown of demographic information is presented in table 1.

Table 2 describes the satisfaction level among Indian pharmacists. The study instrument evaluated the satisfaction of pharmacists by asking questions about the satisfaction with profession, promotional activities, job security, creativity at work, salary and the role of authorities in strengthening profession. Satisfaction score ranged from 1-4 and the cut off of satisfaction was set at $\leq 2$. The data show that only $17.5 \%$ of pharmacists are satisfied with their profession. The findings also suggest that $66.3 \%(n=250)$ participants were satisfied with the balance between their workload and personal life. Similarly, around same number of respondents $(n=245$, $64.98 \%$ ) were satisfied to be called as a pharmacist. On the contrary only $14.58 \%(n=55)$ respondents were satisfied with the role of regulatory authorities regarding their input in the development of profession. The results were not different as only $17.5 \%(n=66)$ pharmacists were satisfied with the promotional opportunities at their workplace. Another important finding of the study was the low satisfaction of pharmacists with their income as only $20.42 \%(n=77)$ pharmacists showed their satisfaction with their salary. Mean satisfactory score of pharmacists was $2.42 \pm 1.14$. 


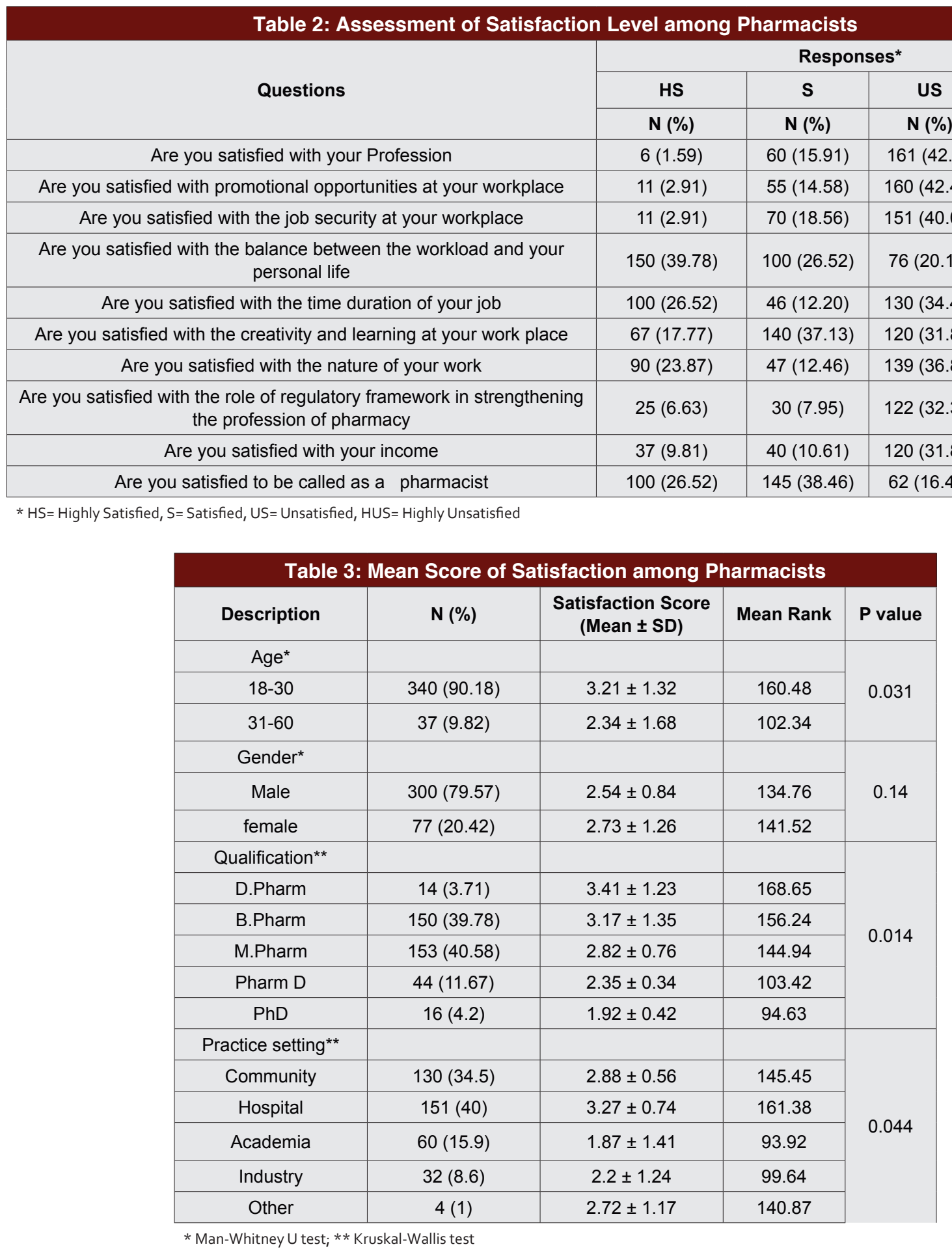

Table 3 expresses the association between independent variables (Age, gender, qualification and practice setting) and their mean satisfaction score. The data show that satisfaction level of young pharmacist was lower as compared to their senior colleagues $(3.21 \pm 1.32$ vs 2.34 \pm 1.68). This difference in satisfaction score was also statistically supported as $\mathrm{p}$ value derived from MannWhitney U test was 0.031 . Although male appeared to be more satisfied with their profession, no statistical differ- ence was observed between the mean satisfaction scores of male and female $(2.54 \pm 0.84$ vs $2.73 \pm 1.26, \mathrm{p}>0.05)$. The findings also suggest that pharmacist with doctorate degree are more satisfied (1.92 \pm 0.42$)$ as compared to pharmacists with lower qualification with Diploma in pharmacy holders were least satisfied $(3.41 \pm 1.23)$. This association was also statistically significant $(\mathrm{p}=0.014)$. The satisfaction level among academicians were highest (1.87 \pm 1.41$)$ followed by industrial pharmacists whose 


\section{Table 4: Respondents' Suggestion for the Improvement of Pharmacists' Role in Future}

\begin{tabular}{|c|c|c|}
\hline \multirow{2}{*}{ Questions } & \multicolumn{2}{|c|}{ Responses (N=377) } \\
\cline { 2 - 3 } Yes (\%) & No (\%) \\
\hline Hiring of pharmacists should be considered mandatory for pharmacists & $270(71.61)$ & $107(28.38)$ \\
\hline Pharmacy degree and national pharmacy licensure should be considered essential in order to \\
acquire procure registration & $320(84.88)$ & $57(15.11)$ \\
\hline Pay scale of pharmacists should be determined on both qualification and experience & $321(85.14)$ & $56(14.40)$ \\
\hline Pharm D graduates should be given the right to prescribe medicines alongside physicians & $250(66.31)$ & $127(33.68)$ \\
\hline Pharm D graduates can be more beneficial to 3.5 years BSc in community health degree holder & $280(74.27)$ & $97(25.72)$ \\
\hline Pharm D graduates can enhance patient safety as compared to B. Pharm, M. Pharm graduates & $240(63.66)$ & $137(36.34)$ \\
\hline Continuous education should be made compulsory for renewing pharmacy licensure & $270(71.61)$ & $107(28.38)$ \\
\hline Diploma of pharmacy holders should be given the position of assistant pharmacist only & $249(66.04)$ & $128(33.95)$ \\
\hline Bachelor of Pharmacy graduates should be given jobs only in industry and related sector & $265(70.29)$ & $112(29.70)$ \\
\hline Pharm D graduates should be placed in hospital, clinical and community settings. & $276(73.20)$ & $101(26.79)$ \\
\hline
\end{tabular}

mean score was $2.2 \pm 1.24$. Hospital pharmacists were observed to be least satisfied with their profession with the mean score of $3.27 \pm 0.74, \mathrm{p}=0.044$.

Respondents' suggestions were also evaluated for the improvement of pharmacists' role in future. One of the two suggestions which were highly agreed by the participants was that the pay scale of pharmacists should be determined by the both qualification and experience $(85.14 \%)$. The other highly agreed suggestion was the consideration of pharmacy degree to be made essential in order to procure registration (84.88\%). The suggestion which was least endorsed by the participants was the superiority of Pharm D course to enhance patient safety as compared to Bachelors and Master of Pharmacy courses. Similar results were viewed as not many participants $(66.31 \%)$ think that pharmacists should be given the right to prescribe alongside physicians. The other highlight of the results was $74.27 \%$ pharmacists believed that Pharm $\mathrm{D}$ graduates can be more beneficial than BSc in commu- nity health degree holders to optimize patient care. The complete information about participants' suggestions for improvement of pharmacists' role is presented in table 4 .

This study also assessed the reasons of dissatisfaction among pharmacists and found that inappropriate government policies were the major reason of dissatisfaction reported by pharmacist $(68.7 \%)$. This is followed by low level of income (21.22\%), lack of management in pharmacy council $(6.89 \%)$ and workload $(3.18 \%)$ respectively. The information is depicted in figure 1.

\section{DISCUSSION}

Several studies have reported that job satisfaction dramatically influences the pharmacist practice settings. ${ }^{7,18}$ For this reason we chose a web-based survey as it is a more flexible form of data collection and has a low refusal rate compared to that of field studies. Our findings showed that only $17.5 \%$ respondents were satisfied

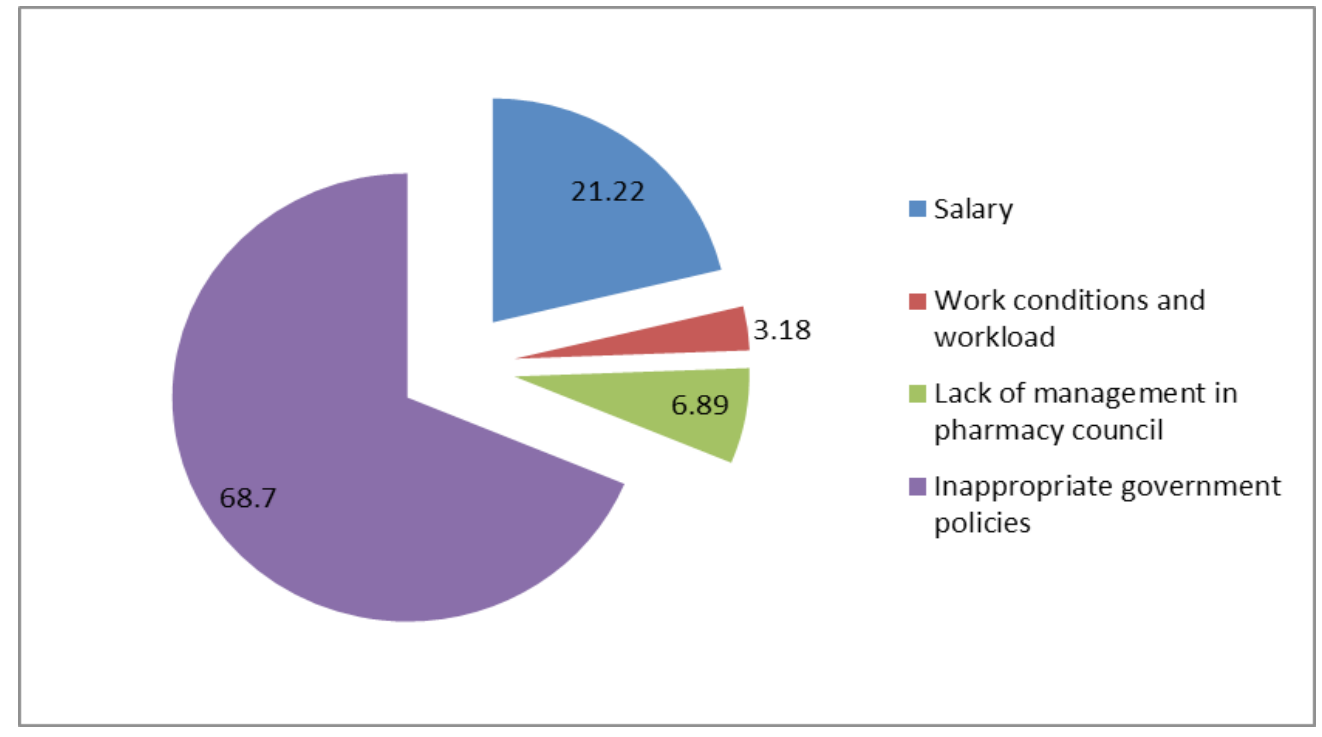

Figure 1: Reasons of dissatisfaction among pharmacists 
with their profession. According to drug and cosmetic act of India, presence of pharmacist or approved chemist and relevant facilities are considered mandatory for running pharmaceutical industry. The same act has also emphasized on the role of pharmacist in hospital and community settings. However, lack of implementation of this rule by stakeholders may have resulted in discouragement and dissatisfaction of pharmacists. In this study, the largest percent of respondents felt dissatisfied with their income irrespective of education levels and field of practice. Surprisingly, majority of the respondents $(82.4 \%)$ were not satisfied about the opportunities to get promoted at their current work place and security of their job, which may have aided to higher rate of dissatisfaction. This finding is in line with similar studies conducted in South India, ${ }^{17-18}$ South Africa, ${ }^{20}$ Malaysia $^{21}$ and Pakistan..$^{22}$ On the other hand, pharmacists working in, Saudi Arabia ${ }^{23} \operatorname{Iran}^{24}$ and $\mathrm{UK}^{4,25}$ who do not face similar issues, were satisfied with their work.

Based on our results, around $47 \%$ of the respondents agreed that their job affected their personal life. The likely reason of high rate of dissatisfaction with the workload could be the long working hours, leading to moderate interest or no interest in work. Work hours affect both productivity and personal well-being. ${ }^{25}$ The other possible reasons could be shortage of staff and/ or working on shifts with stress may affect the personal time of professionals. These findings are in accordance to a study conducted by McCann et al (2009) which found that 39\% pharmacists agreed that they were stressed with work related activities. ${ }^{25}$

Majority of the respondents $(85.4 \%)$ believed that the Indian regulatory frame work has failed to strengthen the pharmacy profession. Yet, $64.5 \%$ of the respondents were satisfied to be called as a pharmacist. In this study, $71.61 \%$ of the participants agreed that only pharmacists should work in pharmaceutical industry unlike the current situation, where non-pharmacist graduates are involved in manufacturing of drugs. ${ }^{18}$ These graduates do not have any professional drugs and medical knowledge and they might get hired solely for the reason that they could be paid a lower salary compared to pharmacy professionals who would have to be paid a higher salary. A majority of the respondents agreed that there is a need for a nationwide pharmacy licensure exam after obtaining a degree like other developed countries and that the pay scale must be based on qualification and experience. Respondents also agreed that PharmD graduates should have the right to write a prescription besides a physician $(66.3 \%)$. Currently, many quacks and alternative physicians are doing practice with allopathic medicines but they don't have sufficient knowledge about proper diagnosis, pharmacology and therapeutics. ${ }^{18}$ The ratio of physicians in rural India is 0.39 per 1000 people as opposed to urban India where the ratio is 1.33 per 1000 people. ${ }^{26-27}$ The total number of physicians in India are $6,77,000$ and $70 \%$ of which work in urban areas. ${ }^{27}$ Unlike India, in many western countries such as US, Belgium, UK, Netherlands, Nordic countries, Switzerland, New Zealand and Australia, healthcare personnel including nurses and pharmacists perform specialized duties/roles in hospital and other practices such as medication management and limited medication prescribing. ${ }^{27}$ Given the shortage of physicians in India, especially in the rural parts, healthcare personnel other than physicians should be allowed to expand the scope of their practice.

The PharmD graduates have specialized clinical knowledge in terms of drug safety compared with our conventional pharmacists. There was consensus among the respondents that continuing education should be made mandatory for renewal of pharmacy registration in respective states. Currently all the Indian pharmacy courses are industry and research oriented, but there is no course other than Pharm. D and M. Pharm (in Pharmacy Practice) with a focus on patient care and the opportunities are very minimal for clinical pharmacists in actual practice settings. In addition to studying the professional status of pharmacists, there is a need to focus on the impact of other intrinsic and extrinsic factors on pharmacist satisfaction in order to devise suitable strategies to improve the same. There is a need for reforming the structure and policies of governing body like Pharmacy Council of India (PCI) as this organization plays an important role in policy making regarding pharmacy practice in India. ${ }^{28}$

\section{STUDY LIMITATIONS}

The results of this study should be interpreted with consideration of the limits of measurement of satisfaction, analysis of data and recruiting methods of participants which could limit the generalizability of these results. Future studies that measure job satisfaction and evaluate the changing responsibilities performed by pharmacists could validate these results.

\section{CONCLUSION}

This study revealed that the satisfaction level of Indian pharmacists is lower than other countries. Age, qualification and practice setting significantly affected the mean satisfaction score. Inappropriate role of regulatory authorities in the development of pharmacy profession is the major reason of dissatisfaction among pharmacist. The policy makers should consider the results and apply the concepts to raise employee satisfaction at their respective workplace. 


\section{SUMMARY}

- The satisfaction rate of pharmacists was $17.5 \%$.

- $68.7 \%$ participants believed the reason for dissatisfaction was irresponsible government policies which hamper pharmacists from seeking jobs compared with other professionals.

- Majority of pharmacists agreed with the suggestion of determining pay scale on the basis of both qualification and experience $(85.1 \%)$ followed by $84.8 \%$ who agreed that pharmacy degree should be deemed essential to acquire registration.

- Study suggest that pharmacist with PhD are more satisfied (1.92 \pm 0.42$)$ as compared to pharmacists with lower qualification with $\mathrm{D}$. Pharm holders were least satisfied $(3.41 \pm 1.23)$.

- $66.31 \%$ participants think that pharmacists should be given the right to prescribe alongside physicians and $74.27 \%$ pharmacists believed that PharmD graduates can be more beneficial than BSc in community health degree holders to optimize patient care in rural areas.

- A further need to look at the intrinsic and extrinsic factors associated with pharmacist satisfaction can aid the development of suitable interventions to improve the same.

\section{About Authors}

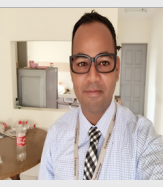

Dr. Akram Ahmad: He is a pharmacy academic and has taught pharmacy practice \& clinical pharmacy, in leading Universities in India and Malaysia. His research programme covers areas related to drug safety, pharmaceutical education, pharmaceutical policy, encompassing access and affordability of medicines, quality use of medicines in community and pharmacoeconomics. He has 60 nos. of journal paper; 7 nos. of abstract; one book. He is a reviewer and editorial board members in several journals of medicine and pharmacy.

\section{ABBREVIATION}

$\begin{array}{ll}\text { PCI } & \text { : Pharmacy Council of India } \\ \text { Pharm D } & \text { : Doctor of Pharmacy) } \\ \text { M. Pharm } & \text { : Master of Pharmacy } \\ \text { B. Pharm } & \text { : Bachelor of Pharmacy } \\ \text { D. Pharm } & \text { : Diploma in Pharmacy } \\ \text { PhD } & \text { : Doctor of philosophy }\end{array}$

\section{REFERENCES}

1. Armstrong M. A Handbook of Human resource Management Practice. Kogan Page Publishing, London, Tenth Edition; 2006.

2. Bowling NA. Is the job satisfaction-Job performance relationship spurious? A meta-analytic examination. J Vocat Behav. 2007; 71(2): 167-85.

3. laffaldano MT, Muchinsky PM. Job satisfaction and job performance: A metaanalysis. Psychol Bull. 1985; 97(2): 251

4. Seston E, Hassell K, Ferguson J, Hann M. Exploring the relationship between pharmacists job satisfaction, intention to quit the profession, and actual quitting. Res Social Adm Pharm. 2009; 5(2): 121-32.

5. McHugh PP. Pharmacists attitudes regarding quality of work life. J Am Pharm Assoc. 1999; 39(5): 667-76.

6. Koustelios A. Personal characteristics and job satisfaction of Greek teachers. Int J Edu Manag. 2001; 15(7): 354-8.

7. David H. Job satisfaction and motivation of health workers in public and private sectors; cross sectional analysis from two Indian states. Hum Resour Health. 2010; 8(27): 1478-4491.

8. Mischa W. Motivation and retention of health workers in developing countries; a systematic review. BMC Health Serv Res. 2008; 8(247): 1472-6963.

9. Aziri B. Job Satisfaction: A Literature Review. Manag Res and Prac. 2011; 3(4): 77-86.

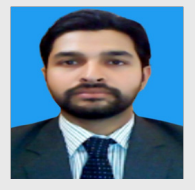

Mr. Muhammad Umair Khan is currently working as a lecturer in UCSI University, Malaysia. He completed his Masters from University of Sunderland, UK in Pharmacotherapy and Medicine Management. He has more than 8 years of professional and teaching experience in national and international organisations. He has published many articles in national and international reputable journals. His area of research includes pharmacy education, pharmacoepidemiology and social aspects of pharmacy.
10. Schafheutle EI, Seston EM, Hassell K. Factors Influencing Pharmacist Performance: A review of the peer-reviewed literature. Health Policy 2011; 102(2): 178-92.

11. Cooper CL, Rout U, Faragher B. Mental health, job satisfaction and job stress among general practitioners. BMJ. 1989; 298(6670): 366-70.

12. D'Addio AC, Eriksson T, Frijters P. An analysis of the determinants of Job satisfaction when individuals' baseline satisfaction levels may differ. Centre for Applied Micro econometrics (CAM), Department of Economics. University of Copenhagen; 2003.

13. Rose M. Job satisfaction in Britain: Coping with complexity. $\mathrm{Br} \mathrm{J}$ Indus Rel. 2005; 43(3): 455-67.

14. Nicola $\mathrm{H}$. The global pharmacy work force: Systematic review of the literature. Hum Resource Health 2009; 7(48): 1478-4491.

15. Jain V, Priya R, Shubhi R, Preeti S, Ashuthosh P, Yashumati R. Evaluation of job satisfaction and social identity of rural Indian pharmacists. Ind J Pharm Prac. 2013; 6(1): 47-58.

16. Ahmad A, Patel I, Sanyal S, Balkrishnan R, Mohanta GP. A study on drug safety monitoring program in India. Ind J Pharm Sci. 2014; 76(5): 379-86.

17. Jose J, Laxman KT, Rao GMP. Career satisfaction among Indian pharmacists. J Pharm Prac Res. 2005; 35(4): 333.

18. Ahmad A, Patel I. Job satisfaction among Indian pharmacists. J Pharm Bioallied Sci. 2013; 5(4): 326.

19. Raosoft. Sample size calculator. Available at http://www.raosoft.com/ samplesize.html (Accessed January 15, 2015).

20. Kidwell M. Job satisfaction of public sector pharmacists. [Master thesis]. Summer strand. Nelson Mandela Metropole University; 2009.

21. Janahiraman S, Paraidathathu T. Job Satisfaction among Malaysian Pharmacists. J Sain Kesi Malay. 2007; 5(2): 79-90.

22. Jamshed SQ, Ibrahim MIM, Hassali MAA, Khilid S. Perception of Academic Pharmacists Regarding Their Career Growth: A Qualitative Case Study from Pakistan. J Clin Diagn Res. 2010; 4(5): 3075-82.

23. Bawazir SA. Job satisfaction in Saudi community pharmacists. J Pharm Prac Res. 2005; 35(4): 334. 
24. Majd M, Hashemian F, Sisi FY, Majd MJZ. Quality of Life and Job Satisfaction of Dispensing Pharmacists Practicing in Tehran Private-sector Pharmacies. Iran J Pharm Res. 2012; 11(4): 1039-44.

25. McCann L, Hughes CM, Adair CG, Cardwell C. Assessing job satisfaction and stress among pharmacists in Northern Ireland. Pharm World Sci. 2009; 31(2): $188-94$
26. Sharma A, Ladd E, Unni krishnan MK. Healthcare Inequity and Physician Scarcity, Empowering Non-Physician Healthcare. Economic and Political Weekly (EPW) 2013; 48(13): 112-7

27. Rao M, Rao KD, Shiva Kumar AK, Chatterjeeand M, Sundararaman T. Human Resources for Health in India. The Lancet 2011; 377(9765): 587-98.

28. Ahmad A, Atique S, Balkrishnan R, Isha Patel. Pharmacy profession in India: Current scenario and Recommendations. Ind J Pharm Edu Res. 2014; 48(3): 1-4. 